\title{
EVALUASI KINERJA SIMPANG GKB KEBOMAS TERKAIT PEMBANGUNAN UNDERPASS GRESIK
}

\author{
Adhi Muhtadi ${ }^{1}$, dan M. Shofwan Donny Cahyono. ${ }^{2}$ \\ ${ }^{1}$ Adhi Muhtadi, Universitas Narotama, email: adhimuhtadi1974@gmail.com \\ ${ }^{2}$ M. Shofwan Donny Cahyono, Universitas Widya Kartika, email: shofwan_dc@yahoo.com
}

\begin{abstract}
ABSTRAK
Pembangunan Underpass Gresik dirasakan sudah sangat mendesak. Pembangunan Underpass Gresik tersebut untuk mempersingkat jarak dan waktu tempuh dari sisi Barat ke Timur Jl. Dr. Wahidin S. Gresik atau sebaliknya. Dalam masa pembagunan Underpass dan setelahnya dibutuhkan kajian lalu lintas agar tidak menggangu kinerja Simpang Dr. Wahidin S. Hal ini mengingat Jl. Dr. Wahidin S. adalah jalan nasional yang menampung kendaraan dari beberapa jalan yang terkait diantaranya adalah Jl. Sumatera, Jl. Raya Gresik - Babat, Jl. Mayjen. Sungkono, Jl. Raya Kembangan Asri, dan Jl. Raya Gresik Lamongan. Jadi permasalahan dalam makalah ini adalah memprediksi kinerja simpang selama pembangunan Underpass dan setelah Underpass pasca operasional.Pengukuran kinerja simpang GKB Gresik bersinyal yang berdasarkan MKJI 1997. Metode penelitian yang digunakan adalah melakukan survey lalu lintas selama 24 jam 7 hari berturut-turut. Setelah mendapatkan volume lalu lintas tiap jamnya, maka akan dihitung kinerja simpang pada kondisi sebelum dibangun. Setelah itu baru memperkirakan perpindahan arus lalu lintas selama pembangunan dan setelah Underpass beroperasi. Dari hasil perhitungan tersebut akan tampak hingga tahun berapa Underpass mampu membantu menurunkan derajat kejenuhan Simpang bersinyal GKB Kebomas tersebut. Sehingga solusi permasalahan dari penelitian ini dapat terungkap.
\end{abstract}

Kata kunci: Kinerja, Simpang bersinyal, Pembangunan Underpass, Gresik

Setiap makalah harus dimulai dengan abstrak kurang lebih 350 kata dan disertai dengan kata kunci. Disarankan abstrak ditulis dalam bahasa Indonesia atau bahasa Inggris (sesuai dengan isi makalah). Abstrak harus dapat mendeskripsikan secara singkat dari masalah, pendekatan, hasil dan kesimpulan dari pekerjaan yang dilakukan. Isi abstrak meliputi latar belakang, tujuan, metode, hasil dan kesimpulan

\section{PENDAHULUAN}

Rencana pembangunan jalan underpass yang melintang di jalan Dr. Wahidin S. Kecamatan Kebomas diusulkan pada Tahun 2018. Usulan pembangunan jalan underpass ini untuk mengurangi kemacetan arus lalu lintas di jalan yang ada di depan Komplek Perumahan Gresik Kota Baru (GKB) dan sekitarnya. Pembangunan underpass ini merupakan suatu usaha yang dilakukan pemerintah untuk meningkatkan aksesibilitas dalam mendukung pertumbuhan ekonomi serta meningkatkan kesejahteraan masyarakat (Nata, et.al, 2016). Pembangunan underpass secara spesifik adalah juga untuk meningkatkan kapasitas jalan dan memperlancar arus lalu lintas (Agung, 2017). Penyesuaian geometrik jalan juga bisa menjadi alternatif untuk peningkatan kapasitas jalan. Akan tetapi hal tersebut kurang optimal apabila volume kendaraan cukup besar (Pratama, 2015). Apabila kinerja simpang cukup buruk misalnya saja dengan LOS (Level of Service) yang didapatkan C (dengan nilai tundaan henti 15,1 - 25 detik), 


\section{NAROTAMA JURNAL TEKNIK SIPIL \\ e-ISSN: 2460-3430 \\ VOLUME 4 NOMOR 2 NOPEMBER 2020}

maka kemungkinan pembangunan simpang tak sebidang (underpass/flyover) menjadi sangat besar (Suthanaya dan Rosita, 2017).

Untuk kondisi optimal, nilai derajat kejenuhan suatu simpang atau ruas jalan sebaiknya dibawah 0,85 (MKJI, 1997). Hasil perhitungan kinerja Simpang GKB tersebut yang dilakukan pada Maret 2020 telah menunjukkan nilai 0,80. Hal ini berarti kalau tidak dilakukan pengembangan apapun pada Simpang GKB Gresik tersebut, maka nilai derajat kejenuhan di Tahun 2021 akan lebih dari 0,85 dengan asumsi pertumbuhan kendaraan 3\% akibat pandemi Covid 19. Pada kondisi normal asumsi pertumbuhan kendaraan bermotor mencapai 7,69\%/tahun di Gresik (BPS Kab. Gresik, 2011).

Oleh karena itu pembangunan underpass Gresik ini sangat layak dari segi penurunan nilai derajat kejenuhan di Simpang GKB Gresik. Hal ini sesuai dengan hasil penelitian yang dilakukan Ridwan, et.al (2018) yang menyatakan bahwa salah satu kelayakan pembangunan underpass/flyover ditinjau dari nilai derajat kejenuhan lalu lintas.

Pembangunan jalan underpass ini secara strategis akan menghubungkan Gress Mall, Universitas Muhamadiyah, Perumahan Kembangan Asri (sisi Barat Jln. Dr. Wahidin S.H.) dengan SMA Muhamadiyah, SMPN 2 Kebomas serta Perumahan Randuagung Kecamatan Kebomas Gresik.

Rencana pembangunan jalan underpass ini akan dibangun di bawah jalan Dr. Wahidin S., berada di bawah puncak tertinggi (ketinggian bukit 11 meter). Tempat itu ada di sebelah areal SMA Muhammadiyah I Gresik yang saat ini tengah dalam proses pembangunan. Jalan underpass itu melintang ke utara sampai jalan depan sebelah timur Unmuh Gresik.

Selama pembangunan jalan underpass tentu banyak mendatangkan material, alat-alat berat konstruksi dan lainnya. Oleh karena itu agar masyarakat tidak terganggu kemacetan, serta akses keluar masuk komplek perumahan serta akses menuju fasilitas yang lain lebih lancar, maka sangat penting dilakukan kajian lalu lintas pembangunan underpass ini. Khususnya pada Simpang Bersinyal GKB Kebomas Gresik. Agar kinerja lalu lintas selama masa pembangunan tidak terganggu akibat pembangunan Underpass tersebut.

Perlu diketahui bahwa panjang jalan underpass yang akan dibangun kurang lebih 20 meter dengan lebar 7,2 meter. Tinggi terowongan jalan underpass yang melintas dari belahan utara ke selatan tersebut 4,7 meter. Lebar jalan 5,9 meter ditambah trotoar 1,5 meter. 
VOLUME 4 NOMOR 2 NOPEMBER 2020

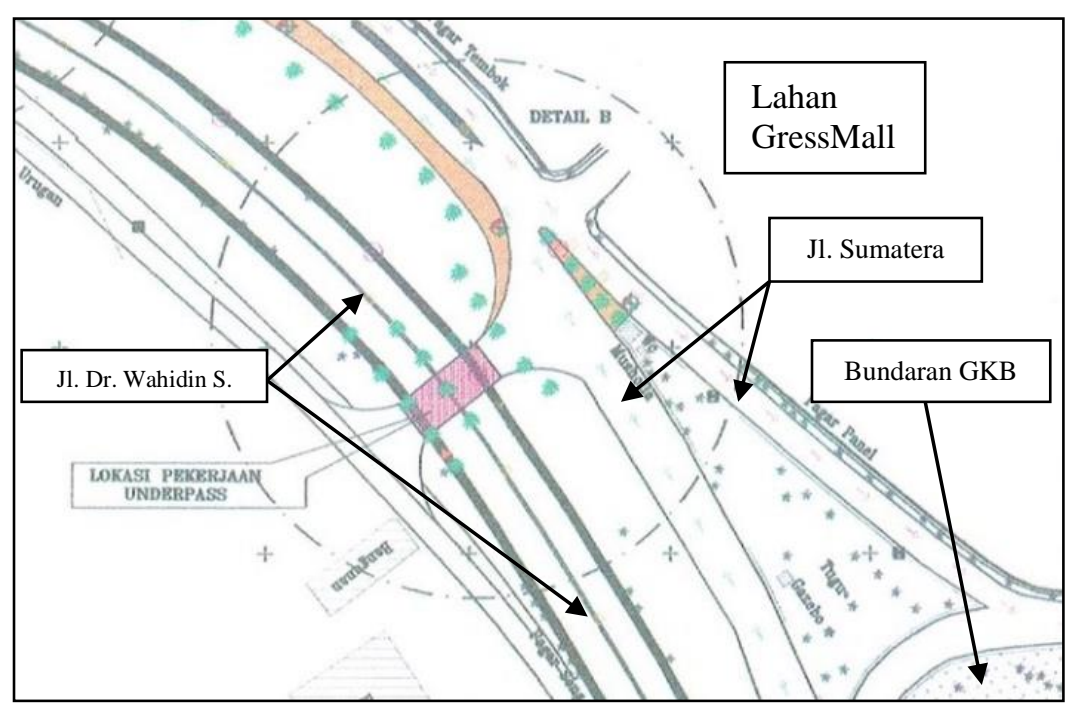

Gambar 1. Site Plan Underpass Gresik

\section{DASAR TEORI}

Makalah di tulis dengan format A4 $(21 \mathrm{~cm}$ x 29,7 cm), dengan batas atas-bawah-kanankiri $3 \mathrm{~cm}$. Font yang digunakan berukuran $12 \mathrm{pt}$ jenis Times New Roman. Format penulisan makalah adalah 1 spasi dan diketik di Microsoft Word. Jumlah halaman makalahpaling banyak 10 halaman.

Pada Simpang GKB terdapat 3 lengan yakni Jl. Dr. Wahidin S. (2 lengan, 2 arah) dan Jl, Sumatera. Sehingga pada simpang terdapat 9 (sembilan) titik konflik lalu lintas seperti pada ilustrasi berikut ini.

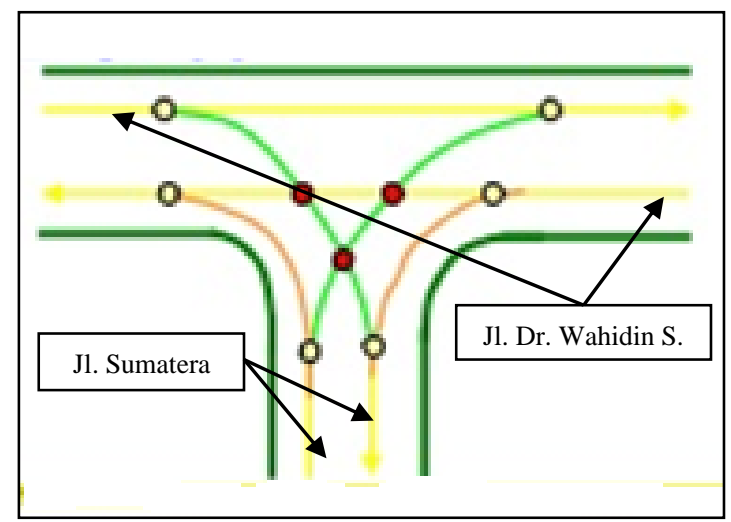

Gambar 2. Titik Konflik pada Simpang 3 Lengan GKB Gresik

Sumber: Survey Lapangan (2020) dan Ulfah (2017)

Pada simpang bersinyal terdapat sinyal merah (berhenti), sinyal hijau (berjalan) dan sinyal antar hijau (kuning). Lama sinyal antar hijau disebut waktu antar hijau.

Waktu antar hijau bertujuan untuk

a. Waktu kuning merupakan peringatan bahwa kendaraan akan berangkat maupun berhenti. Besaran waktu kuning ditetapkan berdasarkan kemampuan seorang pengemudi untuk dapat melihat secara jelas namun singkat, biasanya ditetapkan sebesar tiga detik.

b. Waktu semua merah digunakan untuk memberikan waktu pengosongan (clearance time) sehingga resiko kecelakaan dapat dikurangi. 
Tabel 1: Nilai Normal Waktu Antara Hijau

\begin{tabular}{|l|c|l|}
\hline Ukuran simpang & Lebar jalan rata-rata & Nilai normal waktu antar hijau \\
\hline Kecil & $6-9 \mathrm{~m}$ & 4 det per fase \\
Sedang & $10-14 \mathrm{~m}$ & $\begin{array}{l}5 \text { det per fase } \\
\text { Besar }\end{array}$ \\
\hline
\end{tabular}

Sumber: MKJI (1997)

Tingkat pelayanan pada simpang bersinyal dibagi atas tingkatan : A, B, C, D, E dan F. Pada kondisi operasional yang paling baik dari suatu fasilitas dinyatakan dengan tingkat pelayanan A, sedangkan untuk kondisi yang paling jelek dinyatakan dengan tingkat pelayanan F. Hubungan antara besarnya tundaan henti kendaraan (detik) dengan tingkat pelayanan dapat kita lihat pada tabel berikut.

Tabel 2: Kriteria Tingkat Pelayanan Pada Persimpangan Bersinyal

\begin{tabular}{|c|c|}
\hline Tingkat Pelayanan & Tundaan Henti Tiap Kendaraan (detik) \\
\hline A & $\leq 0,5$ \\
\hline B & $5,1-15,0$ \\
\hline C & $15,1-25,0$ \\
\hline D & $25,1-40,0$ \\
\hline E & $40,1-60,0$ \\
\hline F & $\geq 60,0$ \\
\hline
\end{tabular}

Sumber: HCM (2010)

Faktor-faktor yang mempengaruhi besar arus jenuh adalah jumlah lajur dalam kelompok lajur yang bersangkutan, lebar lajur, persentase kendaraan yang lewat, kemiringan memanjang jalan, adanya lajur parkir dan jumlah manuver parkir perjam, pengaruh penyesuaian kota dan penduduk, hambatan samping sebagai fungsi-fungsi dari jenis lingkungan jalan dan pengaruh membelok kekanan dan kekiri.

Persamaan matematis untuk menyatakan hal diatas digunakan dalam perhitungan arus jenuh sebagai berikut:

$S=S_{0} \times F_{C S} \times F_{S F} \times F_{G} \times F_{P} \times F_{R T} \times F_{L T}$

Dimana:

$\mathrm{S} \quad=$ Arus jenuh untuk kelompok lajur yang dianalisis, dalam kendaraan perjam waktu hijau (smp/jam)

$\mathrm{S}_{0} \quad=$ Arus jenuh dasar untuk setiap pendekatan (smp/jam)

Fcs = Faktor penyesuaian ukuran kota dengan jumlah penduduk

$\mathrm{F}_{\mathrm{SF}} \quad=$ Faktor penyesuaian hambatan samping sebagai fungsi dari jenis lingkungan

$\mathrm{F}_{\mathrm{G}} \quad=$ Faktor penyesuaian kelandaian jalan

$\mathrm{FP}_{\mathrm{P}} \quad=$ Faktor penyesuaian terhadap parkir

$\mathrm{F}_{\mathrm{RT}} \quad=$ Faktor penyesuaian belok kanan (hanya berlaku untuk pendekatan tipe $\mathrm{P}$, jalan dua arah) 
$\mathrm{F}_{\mathrm{LT}} \quad=$ Faktor penyesuaian belok kiri (hanya berlaku untuk pendekatan tipe $\mathrm{P}$, tanpa belok kiri langsung)

Waktu siklus sebelum penyesuaian $\left(\mathrm{C}_{\mathrm{ua}}\right)$ untuk pengendalian waktu tetap, dan hasilnya akan dimasukkan kedalam waktu siklus.

$\mathrm{C}_{\text {uа }}=(1,5 \times \mathrm{LTI}+5) /\left(1-\Sigma \mathrm{FR}_{\text {crit }}\right)$

Dimana:

$\mathrm{C}_{\mathrm{ua}}=$ Waktu siklus sebelum penyesuaian sinyal (det)

$\mathrm{L}_{\mathrm{TI}}=$ Waktu hilang total per siklus (det)

$\mathrm{FR}=$ Arus dibagi dengan arus jenuh $(\mathrm{Q} / \mathrm{S})$

$\mathrm{FR}_{\text {crit }}=$ Nilai FR tertinggi dari semua pendekat yang berangkat pada suatu fase sinyal $\Sigma \mathrm{FR}_{\text {crit }}=$ Rasio arus simpang $=$ jumlah $\mathrm{FR}_{\text {crit }}$ dari semua fase pada siklus tersebut.

Berikut ini ditampilkan pada Tabel 3 tentang waktu siklus simpang bersinyal yang disarankan untuk tipe pengaturan 2 fase, 3 fase dan 4 fase.

Tabel 3: Waktu Siklus Yang Disarankan Untuk Keadaan Yang Berbeda

\begin{tabular}{|l|c|}
\hline Tipe pengaturan & $\begin{array}{c}\text { Waktu siklus yang layak } \\
\text { (det) }\end{array}$ \\
\hline Pengaturan dua-fase & $40-80$ \\
Pengaturan tiga-fase & $50-100$ \\
Pengaturan empat-fase & $80-130$ \\
\hline
\end{tabular}

Sumber: MKJI (1997)

Tundaan pada simpang terdiri dari 2 komponen, yaitu tundaan lalu lintas (DT) dan tundaan geometrik (DG).

$\mathrm{D}_{\mathrm{j}}=\mathrm{DT}_{\mathrm{j}}+\mathrm{DG}_{\mathrm{j}}$

Dimana:

$\mathrm{Dj} \quad=$ tundaan rata-rata pendekat $\mathrm{j}(\mathrm{smp} / \mathrm{jam})$

$\mathrm{DTj}=$ tundaan lalu lintas rata-rata pendekat $\mathrm{j}$ (detik/smp)

$\mathrm{DGj}=$ tundaan geometrik rata-rata pendekat (detik/jam).

\section{METODOLOGI PENELITIAN}

Pada penelitian dilakukan dengan 5 langkah utama yakni:

1. Melakukan input data yang dihasilkan dari data survey lapangan

a. Data geometrik, data pengaturan lalu lintas, dan data kondisi lingkungan

b. Kondisi arus lalu lintas

2. Penggunaan Sinyal
a. Fase awal
b. Waktu antar hijau dan waktu hilang

3. Penentuan Waktu Sinyal

a. Tipe pendekat 
b. Lebar pendekat aktif

c. Arus jenuh dasar

d. Faktor-faktor penyesuaian

e. Rasio arus/Arus jenuh

f. Waktu siklus dan waktu hijau

4. Kapasitas

a. Kapasitas

b. Keperluan untuk perubahan, pada langkah ini dapat dilakukan ubah penentuanfase sinyal, lebar pendekat, aturan membelok dsb.

5. Perilaku Lalu Lintas
a. Persiapan
b. Panjang Antrian
c. Kendaraan Terhenti
d. Tundaan

\section{PEMBAHASAN}

Dari hasil survai dihasilkan jumlah satuan mobil penumpang per jam (SMP/Jam). Hal ini didapatkan volume total kendaraan ringan (LV), Kendaraan Berat (HV) dan Sepeda Motor (MC) pada analisis umum terlihat bahwa jam puncak total kendaraan berada pada jam sore 17.00 - 18.00. Lokasi survey Simpang GKB Gresik dapat dilihat pada Gambar 3. Grafik Analisa kendaraan dapat dilihat pada Gambar 4 Satuan mobil penumpang per jam (SMP/ Jam).

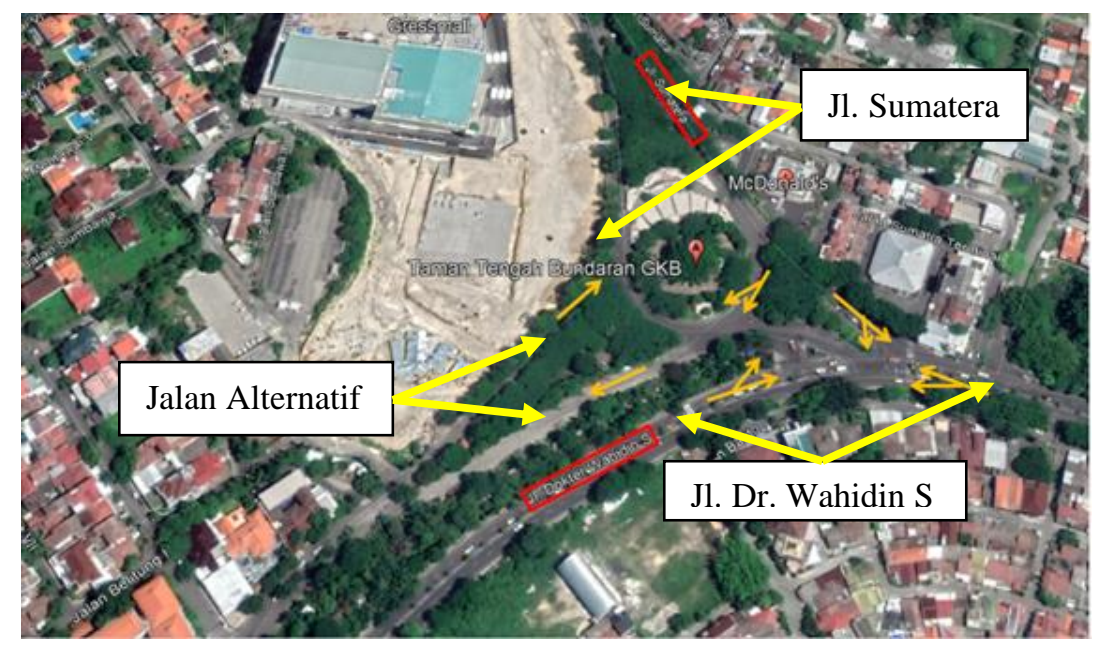

Gambar 3. Lokasi Survey dan Arah Lalu Lintas Simpang GKB Gresik.

Berikut ini hasil survey pada jam puncak di Simpang Jl. Dr. Wahidin Sudiro H. - Jl. Randu Agung - Jl. Sumatera selama 7 x 24 jam mulai Tanggal 22 Pebruari 2020 hingga 28 Pebruari 2020. 


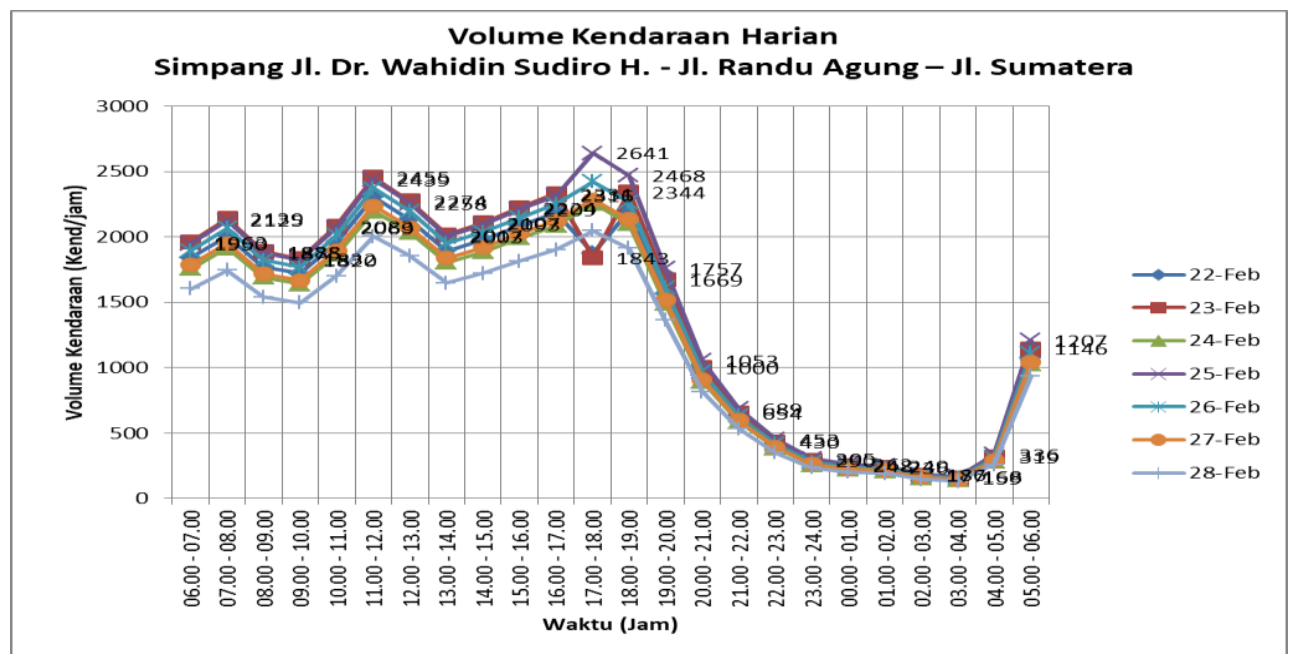

Gambar 3. Volume Kendaraan Harian di Simpang GKB Gresik (SMP/ Jam)

Tabel 4: Volume Jam Puncak di Simpang GKB Gresik.

\begin{tabular}{|l|c|}
\hline Tanggal & Jam Puncak (smp/jam) \\
\hline 22 Peb & 1875 \\
\hline 23 Peb & 1843 \\
\hline 24 Peb & 2258 \\
\hline $\mathbf{2 5}$ Peb & $\mathbf{2 6 4 1}$ \\
\hline 26 Peb & 2422 \\
\hline 27 Peb & 2284 \\
\hline 28 Peb & 2047 \\
\hline
\end{tabular}

Sumber: Rekap Data Survey (2020)

Dari penggambaran grafik di atas dan tabel jam puncak, maka dapat diketahui bahwa volume lalu lintas tertinggi adalah pada Hari Selasa tanggal 25 Pebruari 2020 pukul 17.00 - 18.00 WIB. Oleh karena itu, volume lalu lintas tersebut akan dijadikan dasar perhitungan kinerja Simpang GKB Gresik.

Berikut ini hasil perhitungan MKJI 1997 untuk Simpang Bersinyal GKB Gresik.

Tabel 5: Perilaku Lalu Lintas di Simpang GKB Gresik pada Tahun 2020

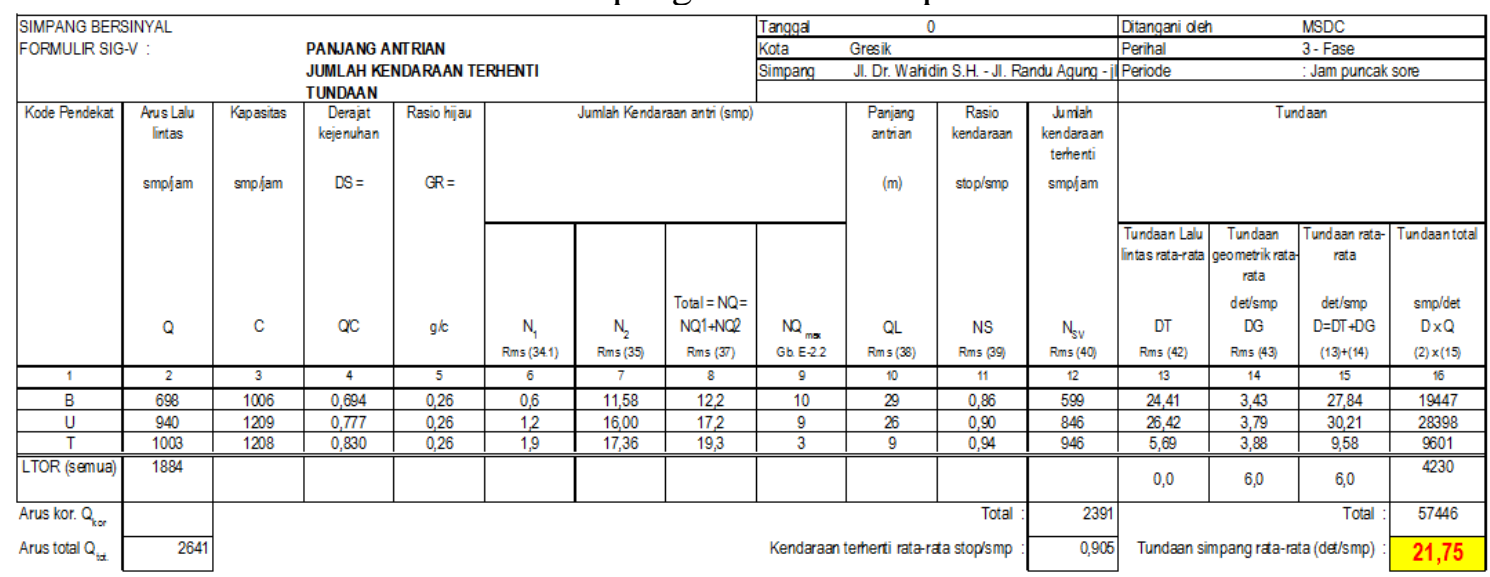

Tampak bahwa nilai tundaan simpang rata-rata telah mencapai 21,75 (detik/smp). Nilai ini sudah termasuk LOS C (cukup buruk) dan dikhawatirkan akibat adanya mobilitas 


\section{NAROTAMA JURNAL TEKNIK SIPIL}

e-ISSN: 2460-3430

VOLUME 4 NOMOR 2 NOPEMBER 2020

proyek underpass Gresik, maka nilai LOS di Tahun 2021 akan menjadi turun (D atau E).

Berikut ini hasil perhitungan MKJI 1997 untuk Simpang Bersinyal GKB Gresik selama masa konstruksi dengan penambahan mobilitas kendaraan proyek underpass Gresik.

Tabel 6: Perilaku Lalu Lintas di Simpang GKB Gresik pada Masa Pembangunan Underpass Gresik Tahun 2020

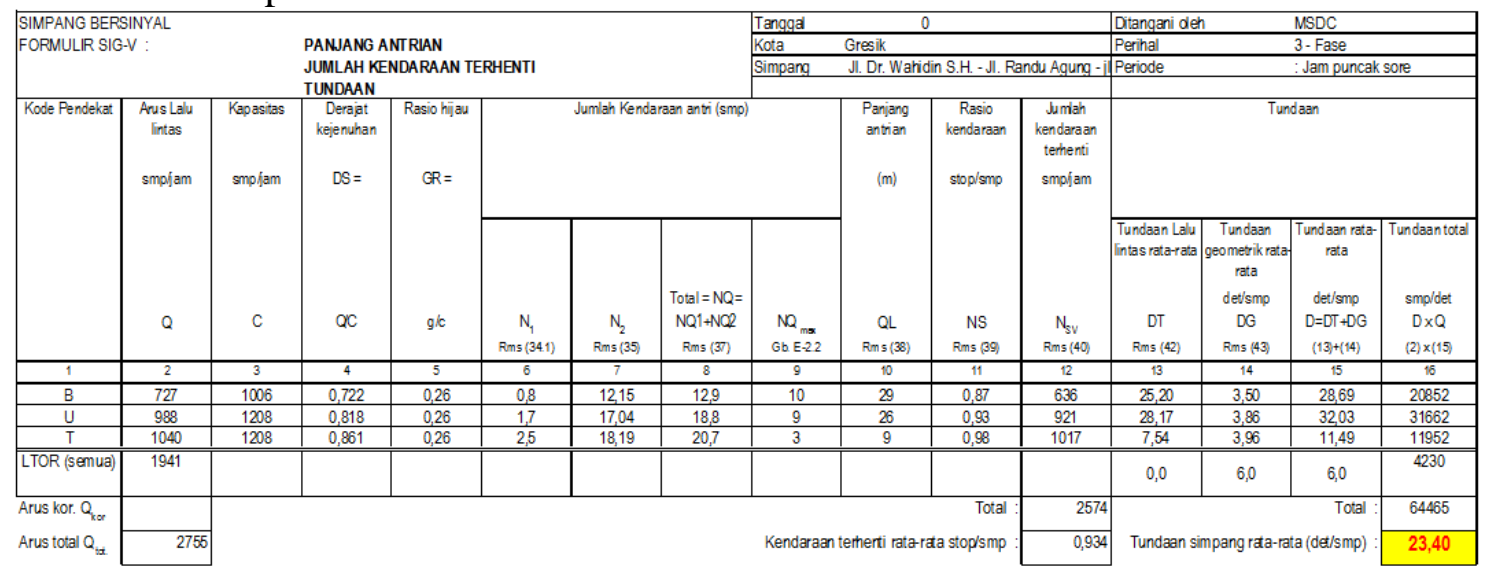

Tampak bahwa nilai tundaan simpang rata-rata naik menjadi 23,40 (detik/smp). Nilai ini masih termasuk LOS C (cukup buruk) dan dikhawatirkan akibat pertumbuhan kendaraan bermotor, maka nilai LOS di Tahun 2021 akan menjadi turun (D atau E).

Perlu diketahui bahwa selama masa pembangunan, maka Jl. Dr. Wahidin S. Akan ditutup selama 3 bulan. Arus lalu lintas akan dialihkan ke frontage road Jl. Sumatera yang langsung menuju di depan UNMUH Gresik.

Berikut ini hasil perhitungan MKJI 1997 untuk Simpang Bersinyal GKB Gresik apabila Unerpass telah beroperasi pada Tahun 2021.

Tabel 7: Perilaku Lalu Lintas di Simpang GKB Gresik pada Masa Pembangunan Underpass Gresik Beroperasi di Tahun 2021

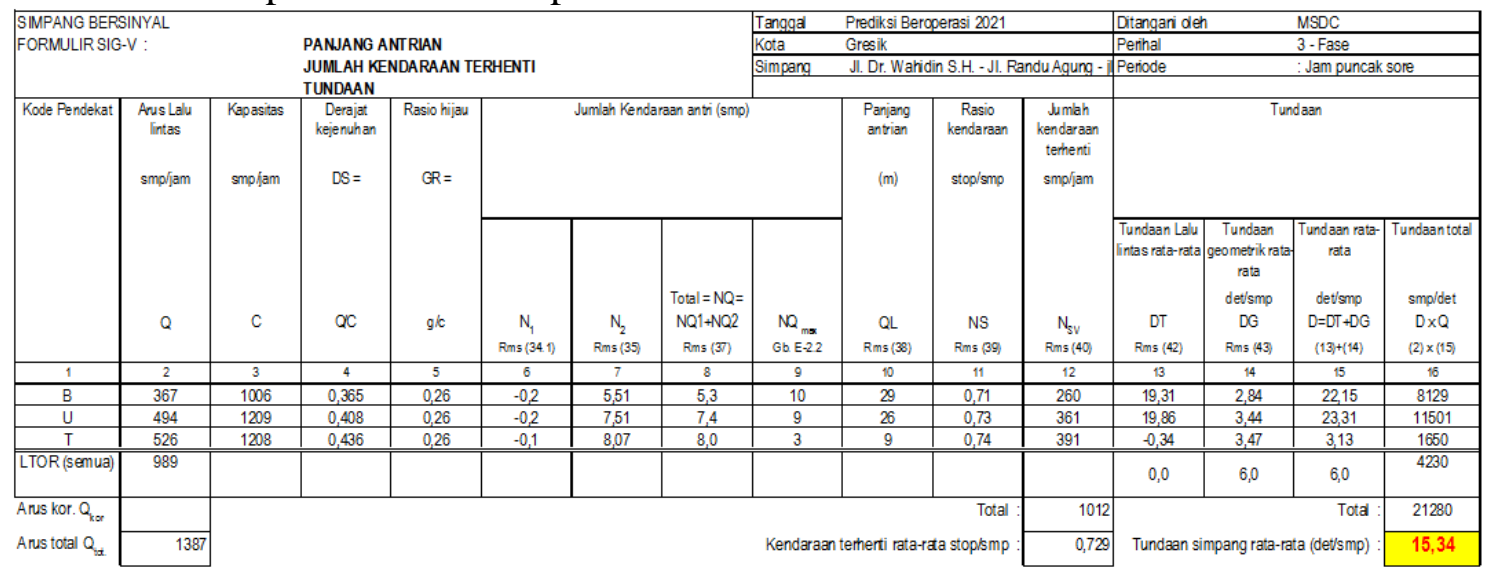

Tampak bahwa nilai tundaan simpang rata-rata naik menjadi 15,34 (detik/smp). Nilai ini mengalami penurunan akan tetapi masih termasuk LOS C. Akan tetapi banyak manfaat yang didapatkan dari pembangunan underpass Gresik contohnya yaitu:

Arus lalu lintas dari sisi UNMUH Gresik apabila akan menuju perumahan Randuagung yang ada di seberang tidak perlu memutar jauh hingga 1,56 km. Maka cukup hanya menempuh 202 meter saja. Hal ini juga tentunya menghemat waktu tempuh, biaya bahan bakar dan biaya perawatan kendaraan. Begitu pula yang terjadi apabila ada 


\section{NAROTAMA JURNAL TEKNIK SIPIL \\ e-ISSN: 2460-3430 \\ VOLUME 4 NOMOR 2 NOPEMBER 2020}

seseorang yang berangkat menuju ke Gress Mall, SMA Muhamadiyah, SMPN 2 Kebomas, Perumahan Randu Agung dan masih banyak lagi.

\section{KESIMPULAN}

Untuk pokok pikiran menggunakan Times New Roman ukuran 12 pt, justified, 1 spasi, seperti yang Anda lihat dalam contoh ini. Anda diijinkan menggunakan font lain untuk tujuan tertentu misalnya untuk membedakan kode sumber (source code) dari program komputer dengan teks pada subyek. Judul bagian ditulis dengan Times New Roman 14 pt, bold. Penomoran bab dengan angka 1, 2, 3, dan seterusnya.

Permasalahan dalam penelitian ini adalah kinerja Simpang GKB Gresik pada waktu sebelum pembangunan, ketika pembagunan dan setelah pembangunan Underpass Gresik. Berikut ini kinerja Simpang GKB Kebomas Gresik:

1. Sebelum pembangunan:

VCR = 0,694 (Barat/Jl. Dr. Wahidin S.); 0,777 (Utara Jl. Sumatera) dan 0,830 (Timur/Jl. Dr. Wahidin S.)

Tundaan simpang rata-rata $=21,75 \mathrm{detik} / \mathrm{smp}$

2. Masa pelaksanaan pembangunan: 0,722 (Barat/J1. Dr. Wahidin S.); 0,818 (Utara Jl. Sumatera) dan 0,861 (Timur/Jl. Dr. Wahidin S.)

Tundaan simpang rata-rata $=23,40 \mathrm{detik} / \mathrm{smp}$

3. Masa operasional underpass: 0,365 (Barat/Jl. Dr. Wahidin S.); 0,408 (Utara Jl. Sumatera) dan 0,436 (Timur/Jl. Dr. Wahidin S.)

Tundaan simpang rata-rata $=15,34 \mathrm{detik} / \mathrm{smp}$

Terlihat dari segi VCR terjadi penurunan antara sebelum pembangunan dan ketika masaa pembangunan underpass. Apabila underpass selesai dibangun dan bisa beroperasi, maka nilai VCR akan turun hingga kurang 1/2 dari mas pembangunan.

Tundaan simpang rata-rata juga memiliki pola yang sama yakni terjadi penurunan ketika masa pembangunan tetapi tidak drastis. Hanya turun sekitar 1,65 detik/smp.

Akan tetapi nilai tundaan simpang rata-rata ketika underpass telah beroperasi dan Jl. Dr. Wahidin S. Bisa dilalui kembali, maka nilai tundaan simpang rata-rata menjadi 15,34 detik/smp atau turun dari ketika masa pembangunan yakni 8,06 detik/smp. Suatu penurunan nilai simpang tundaan rata-rata yang cukup signifikan dikarenakan adanya pembangunan Underpass Gresik. Hasil penelitian tersebut sejalan dengan hasil penelitian Muhtadi dan Supani (2015) dimana nilai VCR akan turun ketika masa pembagunan selesai dan beroperasinya simpang tak sebidang.

Agar nilai VCR dan tundaan simpang rata-rata di Gresik menjadi rendah, maka sebaiknya Pemerintah Kab. Gresik mengutamakan penyediaan angkutan umum massal yang dapat diandalkan (Muhtadi, et.al., 2012). Sedangkan faktor utama peralihan pengguna kendaraan pribadi ke angkutan umum adalah dari segi tarif angkutan umum yang harus lebih rendah daripada biaya penggunaan kendaraan pribadi dan waktu tempuh angkutan umum harus lebih cepat dari waktu tempuh penggunaan kendaraan pribadi (Muhtadi \&Widyastuti, 2014).

\section{DAFTAR PUSTAKA}

1. Agung, Muh. Dwiyanto (2017) Perencanaan underpass Simpang Mandai Makasar dengan Metode Jack Box Channel, Tidak Dipublikasikan Tugas Akhir, Fakultas Teknik Sipil dan Perencanaan, Institut Teknologi Sepuluh November.

2. Badan Pusat Satatistik (2011), Kab. Gresik Dalam Angka, Gresik: BPS Kab. Gresik 


\section{NAROTAMA JURNAL TEKNIK SIPIL \\ e-ISSN: 2460-3430}

VOLUME 4 NOMOR 2 NOPEMBER 2020

3. Direktorat Jenderal Bina Marga (1997) Manual Kapasitas Jalan Indonesia, Jakarta: Kememterian Pekerjaan Umum

4. Muhtadi, A., Wasono, S.B., Artaya, I.P., dan Mudjanarko, S.W. (2012) Evaluasi Pelayanan Bus dan MPU Kota Surabaya Untuk Menunjang Sistem Transportasi Berkelanjutan, Prosiding Konferensi Nasional Pasca Sarjana Teknik Sipil (KNPTS), Bandung: ITB

5. Muhtadi, A., dan Widyastuti, H. (2014), Prediksi waktu tempuh dan tarif yang diinginkan pengguna sepeda motor untuk menggunakan Trem Surabaya, Prosiding Semnas Teknik Sipil ITS X, pp. $229-237$

6. Muhtadi A., dan Supani (2015), Analisis perilaku lalu lintas sebelum dan sesudah rencana pembangunan simpang tak sebidang Kentungan Yogyakarta, Prosiding Semnas Teknik Sipil ITS XI, pp.409-414

7. Nata, I.G.T.S., Putera, I.G.A.A., dan Gd Astawa Diputra (2016) Analisis resiko pembangunan Underpass Dewaruci, Jurnal Spektran, 4(1), 79-87.

8. Pratama, Theodorus Marvin (2018) Perencanaan underpass Jalan Laksda Adisutjipto Yogyakarta (Studi kasus di persimpangan Jalan Babarasaridan Jalan Laksda Adisutjipto, Tidak Dipublikasikan Tugas Akhir, Fakultas Teknik, Universitas Atma Jaya.

9. Ridwan, M (2018) Studi kelayakan pembangunan underpass/flyover pada jalan Yos Sudarso Simpang Glugur by pass, Tidak Dipublikasikan Tugas Akhir, Fakultas Teknik, Universitas Muhamadiyah Sumatera Utara.

10. Suthanaya, P.A., dan Rosita, N.N. (2016) Kajian Efektivitas Pengelolaan Simpang dengan Underpass (Studi Kasus Simpang Tugu Ngurah Rai di Provinsi Bali), Jurnal Spektran, 5(2), 147-154.

11. Transportation Research Board (2010) Highway Capacity Manual 2010. Washington: TRB of National Academies.

12. Ulfah (2017) Mikrosimulasi Lalu Lintas pada Simpag Tiga dengan Software Vissim, Tidak Dipublikasikan Tugas Akhir, Jurusan Teknik Sipil, Universitas Hasanuddin 